\title{
Investigation of the impacts of design parameters on thermal performance of buildings in cold climate
}

\author{
Rashid Gaitov ${ }^{1}$, Serik Tokbolat ${ }^{2,}{ }^{*}$, Hua Zhong ${ }^{2}$, Mohamad Mustafa ${ }^{3}$ \\ ${ }^{1}$ Dept. of Civil and Environmental Engineering, Nazarbayev University, 53 Kabanbay Batyr Ave, Nur-Sultan, 010000, \\ Kazakhstan \\ ${ }^{2}$ Dept. of Construction Management, Nottingham Trent University, 50 Shakespeare street, Nottingham NG1 4FQ, United \\ Kingdom \\ ${ }^{3}$ Dept. of Building, Energy and Material Technology, UiT The Arctic University of Norway, PO Box 385, Narvik, 8514, \\ Norway
}

\begin{abstract}
While design optimization of buildings seeks to improve energy efficiency and, thus, leads to greenhouse gas emissions reduction, the thermal performance of buildings can be compromised. Thermal performance is an important aspect as it directly affects the health and wellbeing of occupants. This study aims to investigate using a simple simulation tool to examine the correlation between a set of building physical design parameters such as orientation, shading and shape, optimization of which helps to make a positive impact on the thermal performance of the building in a cold climate zone. The thermal performance simulation tool Passive Design Assistant (PDA) was used to build a simulation model and test the interdependence between the design parameters and thermal performance. The results indicate that modifications of building's parameters such as orientation and shape or the addition of shadings lead to improvements of the internal thermal temperature, heat gain and loss, hence the optimal parameters should prevail. A case study for cold climate is analyzed, in Nur-Sultan, Kazakhstan, the optimal orientation for the squared building is $30^{\circ}$ from East to South (building rotated $120^{\circ}$ ) and the optimal building's shape is rectangular, which attracts up to 2.6 times higher solar gains than the square one. Moreover, the use of shadings can regulate the internal temperature of the building by $2{ }^{\circ} \mathrm{C}$. General recommendations based on the findings are made and could be considered in the earlier stage of building design and construction processes.
\end{abstract}

\section{Introduction}

Rapid urbanization and population growth processes in both developed and developing countries lead to increasing pressure on the building sector in terms of the need for new buildings. However, a mere provision of "square meters" is not a sufficient measure. The continuously evolving regulations and construction standards, especially in developed countries, tend to demand delivering more sustainable, energy-efficient and thermally comfortable buildings for occupants than before [1]-[3]. The fact that globally buildings are responsible for nearly $40 \%$ of the total energy consumption and $35 \%$ of carbon dioxide (CO2) emissions justifies such demands [4], [5]. Along with the role of energy use and building sustainability, thermal comfort is becoming a prominent aspect in recent years due to improving living condition requirements and evolving research around the topic of human well-being [6].

According to the American Society of Heating, Refrigerating and Air-Conditioning Engineers [7], thermal comfort is defined as the "degree of subjective satisfaction of humans with the thermal environment".
Various studies have proved that low thermal comfort levels can negatively affect the occupants' productivity, health and overall thermal satisfaction [8], [9]. To ensure comfortable thermal conditions, for example, indoor temperature, air velocity, humidity, etc., various stakeholders need to address these issues in their respective work stages. In this regard, the role of early design was reported to be profoundly critical. According to Echenagucia [10], the design stage presents the greatest chance to ensure high thermal performance by a building. Decisions made at this stage do not only define the future performance of a building but in many instances cannot be changed at later stages. For example, building orientation or shape must be decided at this stage.

Previous studies have looked at the impact of orientation on energy use [11], facade types on environmental performance [3], envelope components on energy use [12], building shape on energy efficiency and wind safety [13]. There is a lack of studies around the thermal comfort aspect in the context of the extreme cold climate zone such as Kazakhstan. Considering the extreme weather conditions with hot summers and cold winters in the case study city, Nur-Sultan, Kazakhstan, 
there is a high demand for energy considerations as heating and cooling demands can cause excessive energy consumption. Therefore, this study considers building orientation, shading and shape and assesses how their modification affects the thermal performance in terms of indoor temperature and heat balance. Such analysis is hard to perform using simple calculations and requires adopting simulation tools.

Over the past 60 years, literally hundreds of Building Energy Simulation (BES) software have been developed, such as IES-VE, TAS, Hevacomp, EnergyPlus, TRANSYS, doe-2, and are in use throughout the building energy community. BES is a widely used tool and has played an important role in improving energy efficiency and optimising building-performance. The core tools in the building energy field are the whole-building energy simulation programs that provide users with key building performance indicators such as energy use and demand, temperature, humidity, and costs. The commercial BES software is instrumental for comprehensive design purposes, not only because it covers legislative requirements such as Building Regulations or local codes (Part L in England and Wales, Section 6 in Scotland and Part $\mathrm{F}$ in Northern Ireland), but also due to its ability to rate the environmental performance or impact of buildings using such rating systems as BREEAM, LEED or GreenStar. In the UK, IES-VE, TAS and Hevacomp have become the first 3 software tools approved by the Department of Communities and Local Government for Part $\mathrm{L}$ building regulations calculation and BREEAM assessment. The BES software will typically provide a fast-calculated load assessment based on simple CIBSE Admittance or ASHRAE Heat Balance methods or more detailed dynamic thermal modelling, which determines how much energy the building will consume during peak heating and cooling situations. The application of these tools in the development of buildings is prevalent across all disciplines, so providing the elemental information required to evaluate building performance. Incorporating building performance analysis into the new-build and refurbishment design process allows architects and engineers to easily assess the comparative merits of different passive solar principles and high-performance building technologies. However, these commercial simulation software tools are expensive and not very user friendly for architects or stakeholders without specific building physical knowledge and simulation experience. Also, they have comprehensive functions that require highly detailed inputs and long simulation time for generating the accurate results, besides, it is incompatible to the architects or clients iterative working need for exploring multiple alternatives at an early stage that requires manageable input [14].

For all building projects, it is critically important at their earliest stages that strategic decisions are made which will determine the success of the development in terms of its energy efficiency and all-round building performance. Decisions made later in the building process are far more costly and potentially less effective. The important step is to undertake some form of building performance modelling early in the process by simple and user-friendly tools.

\section{Methodology}

\subsection{Input data}

The PDA simulation tool was used to develop simulation models to perform the analysis. The models were populated with the data relevant to the case study locality and buildings' assumed parameters. The location of the model is Nur-Sultan, the capital city of Kazakhstan. Nur-Sultan is the second coldest capital in the world [15]. Specific location details are provided in Table 1. The highest temperature that was recorded in Nur-Sultan in July is $41.6{ }^{\circ} \mathrm{C}$ and the lowest temperature was $-51.6{ }^{\circ} \mathrm{C}$ in January [16]. The other parameters concerning the outside temperature, humidity, wind velocity were assumed according to the location's latitude and altitude and obtained from the software library.

Table 1. Location details [17]

\begin{tabular}{|l|l|}
\hline Location & Nur-Sultan \\
\hline Latitude & $51^{\circ} 10^{\prime}$ \\
\hline Altitude & $361 \mathrm{~m}$ \\
\hline
\end{tabular}

The climate parameters for selected months used for simulation are provided in Table 2 .

Table 2. Climate parameters [16], [18]

\begin{tabular}{|c|c|c|c|}
\hline & July & September & December \\
\hline $\begin{array}{c}\text { Avg Ground } \\
\text { Temp }\left({ }^{\circ} \mathrm{C}\right)\end{array}$ & 20 & 15 & -15 \\
\hline $\begin{array}{c}\text { Max Dry Bulb } \\
\text { Temp }\left({ }^{\circ} \mathrm{C}\right)\end{array}$ & 33 & 29 & -8 \\
\hline $\begin{array}{c}\text { Min Dry Bulb } \\
\text { Temp }\left({ }^{\circ} \mathrm{C}\right)\end{array}$ & 8 & 5 & -24 \\
\hline
\end{tabular}

The building design parameters used for the models of different shapes (square and rectangular) are shown in Table 3. It should be noted that in case of square building simulation for various orientations, a window was added only to one side (the North facing window). In the case of comparison of different shaped building models, the windows were assumed to be on all sides. Figure 1 shows the initial orientation of 0 degrees assigned to the Northern orientation (in the case of the rectangle building it was assumed that the elongated wall was facing to the North).

The models were assigned to minimal HVAC system values (Table 3 ) in order to maximize the influence of the analyzed parameters such as model orientation and shape.
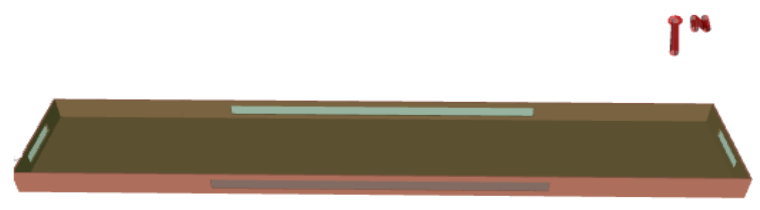

Figure 1. Illustration of the model building 
Table 3. Building model parameters assumptions

\begin{tabular}{|c|c|c|}
\hline Dimensions & Square & Rectangular \\
\hline Length (m) & 45 & 101.25 \\
\hline Width (m) & 45 & 20 \\
\hline Area (m $\left.{ }^{2}\right)$ & 2025 & 2025 \\
\hline Height (m) & 3.7 & 3.7 \\
\hline Occupancy (m²/person) & 10 & 10 \\
\hline Lighting Power Density (W/m²) & 10 & 10 \\
\hline Time Lights On (h) & 8 & 8 \\
\hline Wall construction U/Y-Values & $0.25 / 1$ & $0.25 / 1$ \\
\hline Walls $1 \& 3$ window area (m $\left.{ }^{2}\right)$ & 42 & 94 \\
\hline Walls 2\&4 window area (m²) & 42 & 18.5 \\
\hline Ventilation Rate (ac/h) & 1 & 1 \\
\hline Solar factor & 0.6 & 0.6 \\
\hline U-Value (W/m²K) & 1.54 & 1.54 \\
\hline
\end{tabular}

\subsection{Simulation tool}

Compared with other commercial BES software, Passive Design Assistant (PDA) is a freely available software tool developed to enable conducting simple dynamic thermal calculations in a way that is accessible to a broad range of users, e.g. engineers, architects, and other construction professionals. PDA is to elucidate the principles of passive design and to enable basic design calculations to be conducted, for instance, the assessment of indoor temperatures in naturally ventilated buildings and to compare the energy consumptions for different building shapes with the same floor areas [19].

Furthermore, PDA is a user-friendly tool that can be used to demonstrate the feasibility and benefits of passive design in simple spaces. The tool will help inform designers about the principles of passive design in the earlier building design stage for the following parameters: 1. Orientation, 2. Fenestration and shading, 3. Thermal mass, 4. Internal gains, 5. Building forms. 6. Ventilation. The calculation method used in PDA is the standard CIBSE Simple Dynamic Thermal model. Some further enhancements of the CIBSE method have also been implemented in PDA.

However, The CIBSE Dynamic Thermal Model method assumes that all internal and external loads are represented by a mean or steady-state component plus an alternating component that has 24-hours. The model, therefore, only generates results for a repeating 24-hour period that is a limitation when analyzing results using PDA, which should be observed by all users [20]. The simulation has the time span of one calendar month divided into one-hour intervals, and the results are shown as hourly monthly-averages.

This paper aims to use the PDA tool to examine the optimal passive design for thermal comfort in a typical cold climate zone based on the major passive design principles. The model examines the thermal response of a single square or rectangular space to the different elements important in the development of a passive design strategy, such as Orientation, fenestration, shading, ventilation, thermal mass, internal gains and climate conditions.

The limitations of the results generated by PDA will be discussed. The results of the simulation provide the data about solar, internal, ventilation and fabric heat flows. The overall heat balance, which is the sum of the heat losses, is equal to the sum of the heat gains. Passive design is the reduction of the heat losses of the building. The free heat gains are then almost sufficient to keep the temperature at a comfortable level. However, due to the scope of this study, only solar heat flows are considered.

\section{Results and Discussions}

\subsection{July - building orientation analysis}

The PDA software provides the results of the analysis of the squared building's indoor climate changes affected by the rotation of the building (Figure 2). The side with the window is considered for the orientation variations (only one side of the square building has a window). Figure 3 shows monthly-averaged hourly temperature values. The results presented in the figure show that the highest indoor temperature is when the building is rotated to $120^{\circ}\left(30^{\circ}\right.$ from East to South). This orientation represents the largest sunlight absorptive capacity and results in the highest maximum indoor temperature for squared building. The maximum temperature equals $40.11{ }^{\circ} \mathrm{C}$. On the other side, the lowest building temperature refers to 0 degree orientation (North facing), being $37.42{ }^{\circ} \mathrm{C}$. Therefore, the change of building's orientation may result in a $6.7 \%$ decrease in internal temperature.

It should be noted that since the building models were built based on simple assumptions for the building without heating, ventilation and air-conditioning systems, the internal temperature values may not be equal to required standards.

However, since the design parameters were altered and tested assuming all other parameters were constant and equal to the values, automatically generated by the PDA software. This fact might have caused extremely high indoor temperature values. Therefore, the results of this study should be considered carefully. 


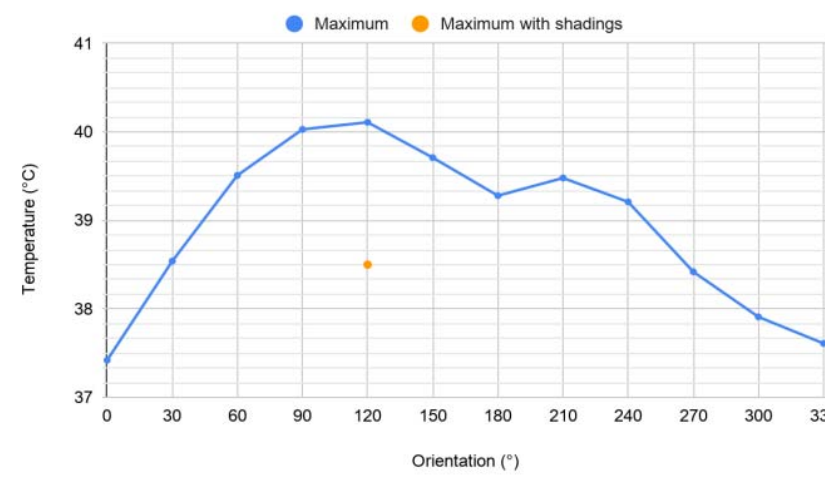

Figure 2. Maximum internal temperature for a square model's different orientations in July

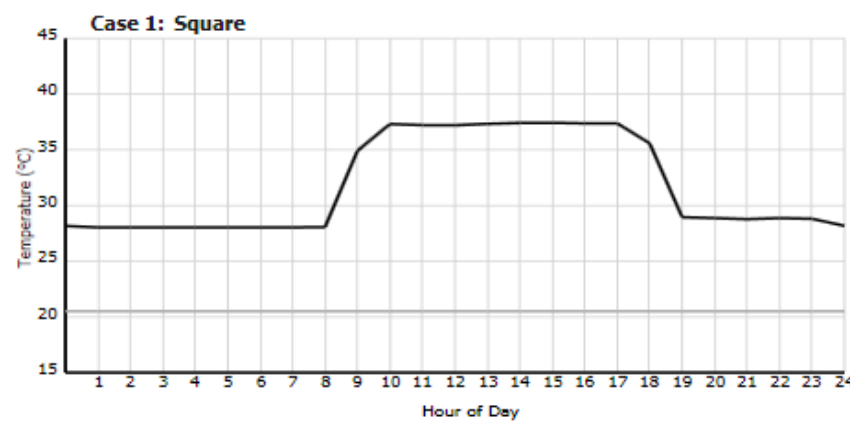

a) $0^{\circ}$ (North) orientation

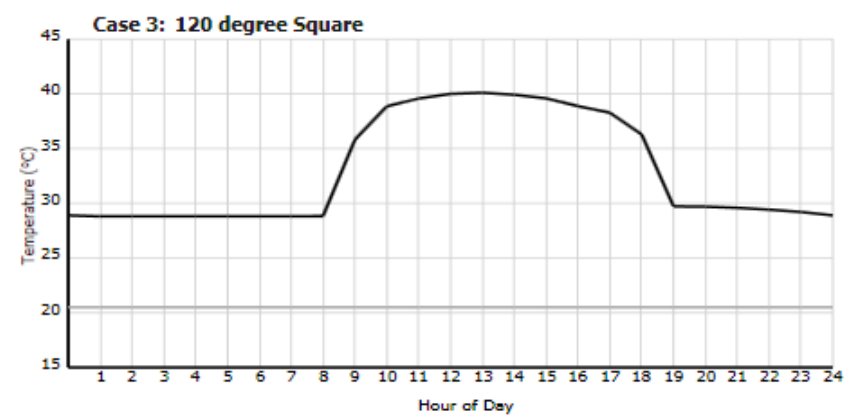

b) $120^{\circ}\left(30^{\circ}\right.$ from East to South) orientation

Figure 3. Temperature results for a squared building

The orientation of the building that showed the highest maximum indoor temperature $\left(120^{\circ}\right)$ is analyzed with addition of shadings. This orientation was chosen in order to see the maximum effect of adding shading by adding it to the side of the building, thus, the orientation with the highest indoor temperature. The results show the effect of the shadings on the room temperature in July (the hottest month). The use of $1 \mathrm{~m}$ long shadings on each of the windows reduces the highest internal temperature by $4 \%$ (from $40.11^{\circ} \mathrm{C}$ to $38.50{ }^{\circ} \mathrm{C}$ ) as shown in Figure 4 . The results show the importance of using shadings, especially in Nur-Sultan during high outdoor temperatures.
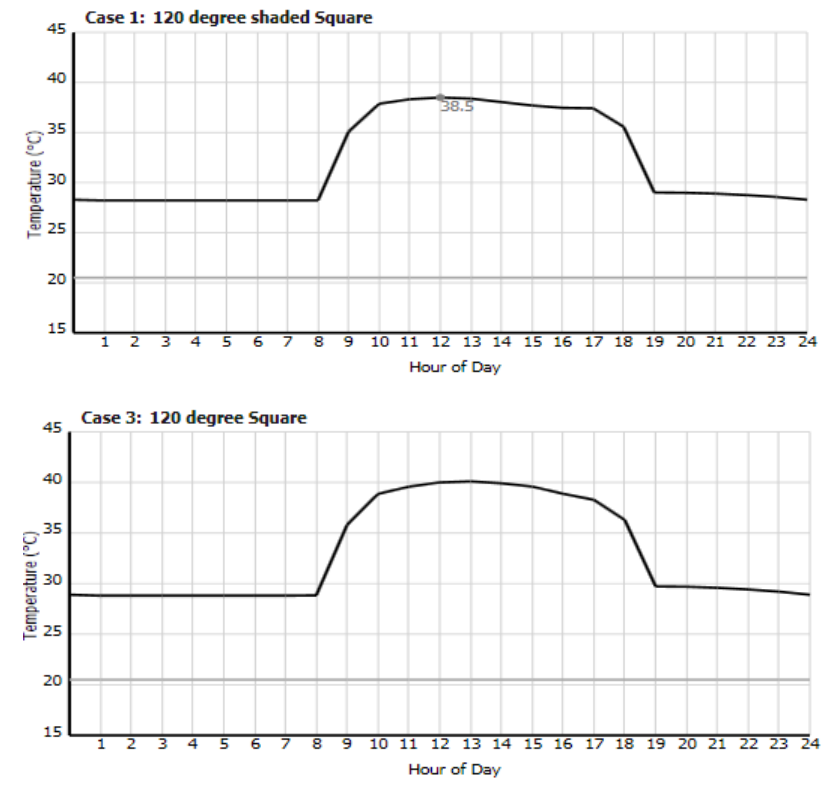

Figure 4. The effect of shadings on the $120^{\circ}\left(30^{\circ}\right.$ from East to South) orientated model

Figure 5 shows the relationship between the maximum solar heat gains of the squared building and the building's orientation in Nur-Sultan in July. The values are average for the month. The chart shows that the highest solar gain in July is at $90^{\circ}$ orientation (East), which corresponds to $18.01 \mathrm{~kW}$ (Figure 5). On the other side, the least result refers to the North facing orientation of the building, which has only $4.03 \mathrm{~kW}$ of solar gain. The analysis of the $120^{\circ}$ oriented model with shadings shows the $42.2 \%$ decrease in solar heat gains.

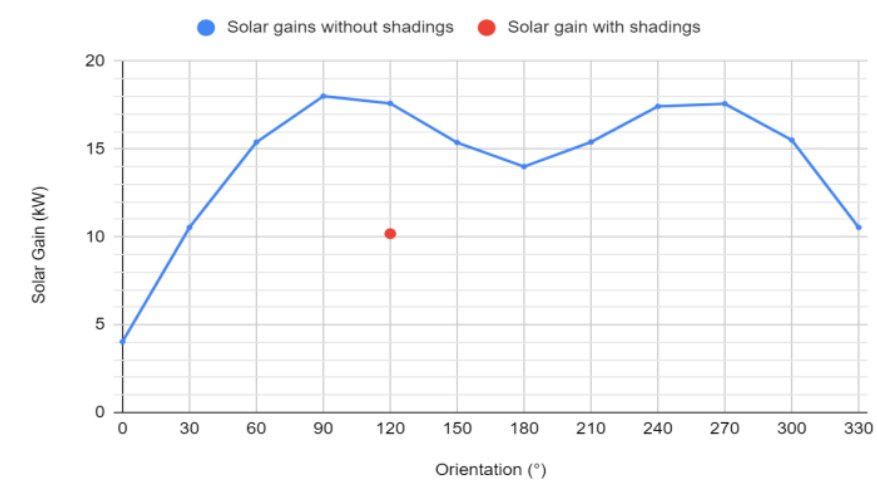

Figure 5. Maximum solar gains for model's different orientations

\subsection{July, September \& December - building shape analysis}

Figure 6 shows the maximum internal temperatures of square and rectangular models during July, September, and December. The highest difference that stands out is in December. Whereas, the maximum temperature in a rectangular building is $8.45^{\circ} \mathrm{C}$, it is $1.88^{\circ} \mathrm{C}$ for a squared building. This is most likely related to the fact that windows are located on all sides, in the case of squared buildings, and winds are quite strong in Nur-Sultan, hence the impact can be great. The rectangular shaped buildings' shorter walls are facing West and East. Since the 
predominant winds in Nur-Sultan are from the West, the building is less affected by wind, thus, causing less impact to the internal temperature [21]. The difference in September is less noticeable, but significant enough to be considered, being about $2{ }^{\circ} \mathrm{C}$, which gives $4.9 \%$ difference. Finally, the analysis for July shows the least difference of $0.6 \%$, where the temperatures for square and rectangular rooms are $42.22^{\circ} \mathrm{C}$ and $41.95{ }^{\circ} \mathrm{C}$ respectively. To conclude, the results show that the internal temperature is most significantly affected by the building's shape in low outdoor temperatures in December.

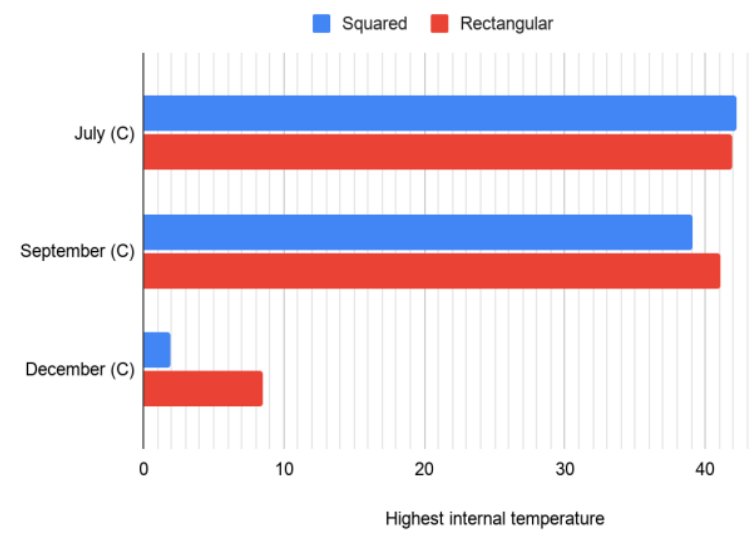

Figure 6. Maximum internal temperature in July, September and December for squared and rectangular models.

Although the change of building shape from square to rectangular significantly affects the internal temperature most significantly in December, the heat gain differences are high in all three months. Figure 7 shows the maximum heat gains of square and rectangular models in three different months, specifically, in July, September and December. The rectangular model has higher values regardless of the change of a month. Its highest heat gains are in September and December, both being equal to 52.76 $\mathrm{kW}$. In July, the rectangular model gains $42.23 \mathrm{~kW}$, whereas the square building has $28.2 \%$ less heat gain $(30.34 \mathrm{~kW})$. For the squared model, the difference between the highest (in September) and the lowest (in December) heat gains is $42.9 \%$. The high difference is mostly due to the changes in solar heat flows, which are discussed in the next paragraph.

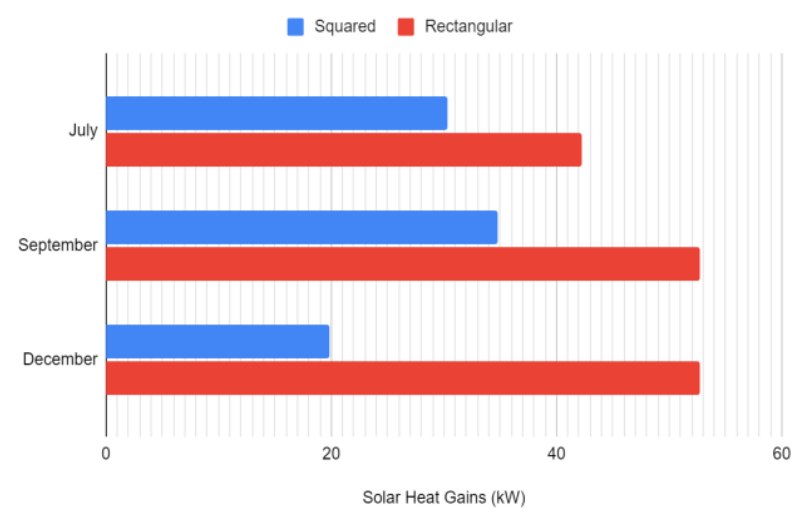

Figure 7. Maximum heat gains for different building shapes in July, September and December
Figures $8 \& 9$ are the heat balance charts that show heat flow changes due to the fabric, sunlight, ventilation and internal heat flows during the day. The charts also show the difference in solar gains in December between squared and rectangular models. Interestingly, the rectangular model absorbs much more energy than the squared model, especially in cold seasons. In the middle of the day, the solar heat flow into the rectangular building peaks at $52.76 \mathrm{~kW}$, which is $165 \%$ higher than that for the square building. In addition, the heat flow into the rectangular building has a wider positive interval, starting at 06:00 and finishing at 20:00 hours compared to the square building, which has a shorter solar gain interval ranging from 08:00 to 18:00 hours.

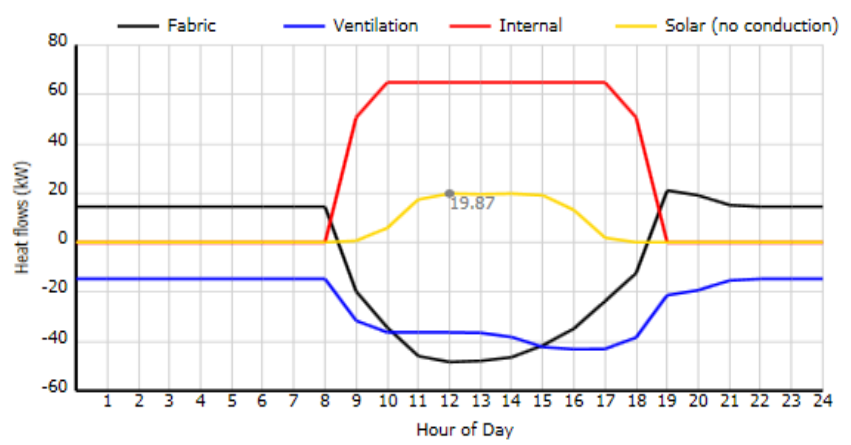

Figure 8. Heat balance chart for the squared building in December

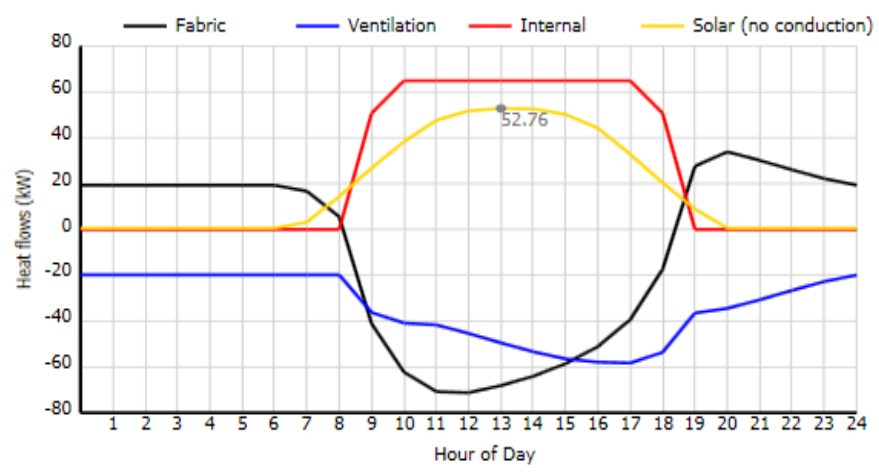

Figure 9. Heat balance chart for the rectangular building in December

\section{Conclusions}

Present-day challenges associated with energy scarcity and carbon dioxide emissions are creating a pressing demand from the building sector to deliver energy-efficient and sustainable buildings. There is also an increasing attention to the thermal performance aspects due to improving living standards. The special attention is given to places with cold climate conditions such as NurSultan city, Kazakhstan which is also known for its hot summers. Designing the building accordingly in such climate conditions is essential to avoid thermal discomfort during buildings' operation stage.

In this study, it was aimed using PDA as the simple simulation tool to assess the impacts of building design parameters such as orientation, shading and shapes. With regards to orientation, the model building was tested for different orientations with one window for the hottest 
month July. The results for July showed that the most energy efficient orientation of the building is $120^{\circ}\left(30^{\circ}\right.$ from East to South). The similar process was done for the solar gain case to understand which orientation is the most optimal. In this case, the $90^{\circ}$ (East) seems to be preferable based on overall heat balance. Identifying the maximum solar gain orientation is particularly useful for the winter season. Then, the orientation, which reached the highest indoor temperature value of $120^{\circ}\left(30^{\circ}\right.$ from East to South), was simulated with the addition of shading in order to understand how the internal comfort was affected. The use of shadings on the windows provided reduction of solar gains by $42.2 \%$ and resulted in a decrease of the maximum indoor temperature by $4 \%$. The results show the importance of using shadings, especially in Nur-Sultan during high outdoor temperatures in summer. To conclude, the findings recommend orienting the buildings in Nur-Sultan at $120^{\circ}\left(30^{\circ}\right.$ from East to South) in order to decrease the use of the heating system by increasing the heat gains. However, the increase in sunlight energy absorption makes it imperative to additionally decrease the temperature during summer, for example, by use of shadings which proved to be effective.

Next, the study looked at the impact of the building shape on the internal temperature and solar gains. Square and rectangular shaped building models of the same area were simulated to identify the optimal shape in terms of internal temperature (in three key months: July, September, and December). The results indicated that the rectangular building has higher solar energy gains than the squared model, mostly in cold seasons. In December, the rectangular model has $165 \%$ higher solar energy absorption, while in July and September the differences are $39.2 \%$ and $51.5 \%$ respectively.

Further, even though the solar gain values were found to be high during the selected three months, the effect of building shape alteration from square to rectangle is most significantly evident during December. In fact, the monthly-average indoor temperature for the rectangular model is higher by $6.57{ }^{\circ} \mathrm{C}$, which gives a threefold increase. The differences in internal temperatures are less obvious in September $\left(2^{\circ} \mathrm{C}\right)$ and lowest in July $\left(0.27^{\circ} \mathrm{C}\right)$.

The study had limitations and assumptions, which have to be taken into consideration while considering this article. For example, the outdoor temperatures in July, September and December are assumed as constant and equal to the monthly average temperatures (Table 2). However, the consideration of the temperature fluctuations during the day in Nur-Sultan would significantly affect the results. Further research should consider the different building sizes and shapes based on the different locations' weather data. In addition, orientations should be tested for winter conditions and should consider the wind impacts.

\section{References}

[1] I. Kovacic and V. Zoller, "Building life cycle optimization tools for early design phases," Energy, vol. 92, pp. 409-419, 2015.
[2] Y. Sun, R. Wilson, and Y. Wu, “A Review of Transparent Insulation Material (TIM) for building energy saving and daylight comfort," Applied Energy, vol. 226, pp. 713-729, 2018.

[3] S. Tokbolat, Y. Naizabekov, and S. Mariani, "The impacts of different façade types on energy use in residential buildings," E3S Web of Conferences, vol. 172, p. 24010, 2020.

[4] "Transition to Sustainable Buildings. Strategies and Opportunities to 2050". IEA, Paris, 2013

[5] I. Artola, K. Rademaekers, R. Williams, and J. Yearwood, Boosting building renovation: what potential and value for Europe? Brussels: European Parliament, 2016.

[6] Z. Gou, "Human factors in green building: building types and users' needs", Buildings, vol. 9, p. 17, 2019.

[7] "Thermal Environmental Conditions for Human Occupancy," Academia.edu. [Online]. Available: https://www.academia.edu/20841731/Thermal_E nvironmental_Conditions_for_Human_Occupanc y. [Accessed: $25-$ Dec-2021].

[8] L. Yang, H. Yan, and J.C. Lam, "Thermal comfort and building energy consumption implications - a review", Appl. Energy, vol. 115, pp. 164-173, 2014

[9] H. M. Kamar, N. Kamsah, F. Ghaleb, and M. I. Alhamid, "Enhancement of thermal comfort in a large space building," Alexandria Engineering Journal, vol. 58, no. 1, pp. 49-65, 2019.

[10] T. M. Echenagucia, A. Capozzoli, Y. Cascone, and, M. Sassone, "The early design stage of a building envelope: Multi-objective search through heating, cooling and lighting energy performance analysis", Appl. Energy, vol. 154, pp. 577-591, 2015.

[11] S. Tokbolat, R.Tokpatayeva, and S. Al-Zubaidy, "The Effects of Orientation on Energy Consumption in Buildings in Kazakhstan,' Journal of Solar Energy Engineering, vol. 135, no. 4, 2013.

[12] S. Tokbolat, F. Nazipov, J. Kim, F. Karaca, "Evaluation of environmental performance of residential building envelope components. Energies (MDPI)," vol. 13, no. 1, p. 174, 2020.

[13] S. Tokbolat, R. Tokpatayeva, S. Al-Zubaidy, "CFD Investigation of the Effect of Building Passive Design Strategy on Energy Efficiency and Wind Comfort in Extreme Weather Conditions in Astana, Kazakhstan," Applied Mechanics and Materials, vols. 253-255, pp. 658669, 2012.

[18] A. Walters, "Digital Energy Estimation Tool (DEET)," Centre for Digital Built Britain, 25May-2020. [Online]. Available:

https://www.cdbb.cam.ac.uk/research/digitalinfrastructure/digital-energy-estimation-tool-deet. [Accessed: 1-Jan-2021].

[15] "The coldest cities in the world," The Active Times, 22-Nov-2019. [Online]. Available: https://www.theactivetimes.com/travel/coldestcities-in-the-world. [Accessed: 1-Jan-2021]. 
[16] "Astana, Kazakhstan Travel Weather Averages," Weatherbase, [Online]. Available: https://www.weatherbase.com/weather/weather.p hp3? $=351881$. [Accessed: 1-Jan-2021].

[17] "Kazakhstan topographic maps, elevation, relief," topographic. [Online]. Available: https://enbw.topographic-

map.com/places/922/Kazakhstan/. [Accessed: 1Jan-2021].

[18] "Nur-Sultan, Nur-Sultan, Kazakhstan Monthly Weather," AccuWeather. [Online]. Available: https://www.accuweather.com/en/kz/nursultan/222343/august-weather/222343.

[Accessed: 1-Jan-2021].
[19] "Passive Design Assistant (PDA)," ARUP, [Online]. Available:

https:/www.arup.com/perspectives/publications/r esearch/section/passive-design-assistant

[20] A. White, M. Holmes, D. J. H. and T. D. Saulles, N. C. (2012) "CIBSE ASHRAE Technical Symposium, Imperial College, London UK - 18 and 19 April 2012", CIBSE ASHRAE Technical Symposium, (April), pp. 1-12.

[21] "Average Weather in Astana, Kazakhstan, Year Round - Weather Spark," WeatherSpark.com, [Online]. Available:

https://weatherspark.com/y/107257/AverageWeather-in-Astana-Kazakhstan-Year-Round. [Accessed: 1-Jan-2021 